\title{
ADVANCES IN CheMistry
}

A Selection of C. N. R. Rao's Publlcations (1994 - 2003) 


\section{WORLD SCIENTIFIC SERIES IN 20TH CENTURY CHEMISTRY}

Consulting Editors: D. H. R. Barton (Texas A\&M University)

F. A. Cotton (Texas A\&M University)

Y. T. Lee (Academia Sinica, Taiwan)

A. H. Zewail (California Institute of Technology)

Published:

Vol. 1: Molecular Structure and Statistical Thermodynamics

- Selected Papers of Kenneth S. Pitzer

by Kenneth S. Pitzer

Vol. 2: Modern Alchemy

- Selected Papers of Glenn T. Seaborg

by Glenn T. Seaborg

Vol. 3: Femtochemistry: Ultrafast Dynamics of the Chemical Bond by Ahmed $H$. Zewail

Vol. 4: Solid State Chemistry

- Selected Papers of C. N. R. Rao

edited by S. K. Joshi and R. A. Mashelkar

Vol. 5: NMR in Structural Biology

- A Collection of Papers by Kurt Wüthrich

by Kurt Wüthrich

Vol. 6: Reason and Imagination: Reflections on Research in Organic Chemistry

- Selected Papers of Derek H. R. Barton

by Derek H. R. Barton

Vol. 7: Frontier Orbitals and Reaction Paths

- Selected Papers of Kenichi Fukui

edited by K. Fukui and H. Fujimoto

Vol. 8: Quantum Chemistry

- Classic Scientific Papers

translated and edited by Hinne Hettema

Vol. 9: The Oxidation of Oxygen and Related Chemistry

- Selected Papers of Neil Bartlett edited with introductory essays by Neil Bartlett

Vol. 10: Linus Pauling

- Selected Scientific Papers

edited by Barclay Kamp, Linda Pauling Kamb, Peter Jeffress Pauling,

Alexander Kamb and Linus Pauling, Jr.

Vol. 11: Across Conventional Lines - Selected Papers of George A. Olah edited by George A. Olah and G. K. Surya Prakash 


\section{World Scientific Series in 20th Century Chemistry - Vol. 12}
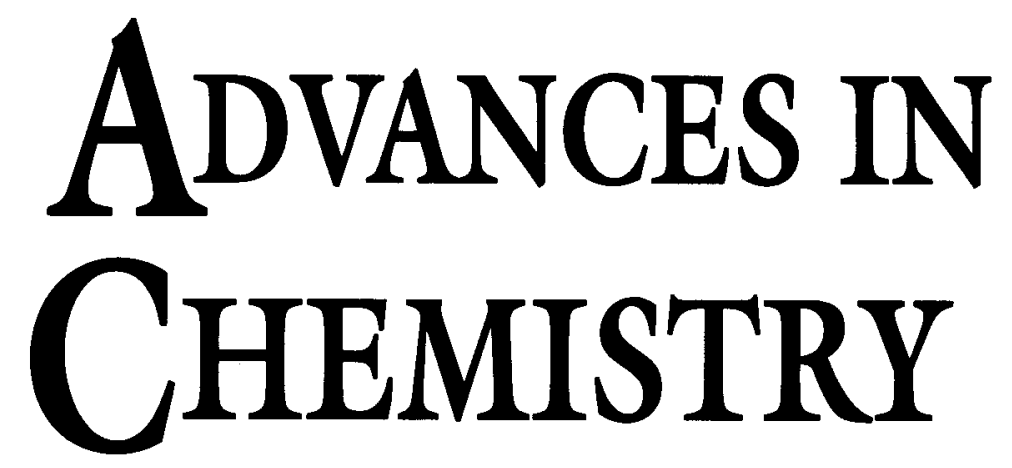

A Selection of C. N. R. Rao's Publications (1994 - 2003)

\section{Editors}

\section{J. Gopalakrishnan}

Indian Institute of Science

\section{G. U. Kulkarni}

Jawaharlal Nehru Centre for Advanced Scientific Research, India 


\title{
Published by
}

World Scientific Publishing Co. Pte. Ltd.

5 Toh Tuck Link, Singapore 596224

USA office: Suite 202, 1060 Main Street, River Edge, NJ 07661

UK office: 57 Shelton Street, Covent Garden, London WC2H 9HE

British Library Cataloguing-in-Publication Data

A catalogue record for this book is available from the British Library.

The editors and publisher would like to thank the following publishers for their permission to reproduce the articles found in this volume:

The Royal Society of Chemistry (J. Mater. Chem., Chem Commun., Chem. Soc. Rev., Dalton Trans., J. Chem. Soc. Dalton Trans.); American Chemical Society (J. Phys. Chem., Chem. Mater., J. Phys. B, Acc. Chem. Res., J. Phy. D, J. Am. Chem. Soc., Inorg. Chem.); Blackwell Science Publishers (A Chemistry for the 21" Century monograph, IUPAC, Ed. M.W. Roberts;

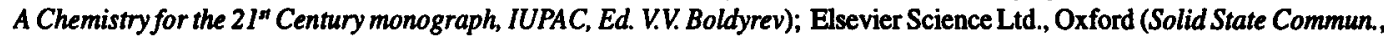
Chem. Phys. Lett., J. Mol. Struct., J. Mol. Struct. (Theochem), Micro. Meso. Mater, Solid State Sci., Mater. Res. Bull., Euro. J. Solid State Inorg. Chem.); Wiley-VCH (Wiley) (Chem. Euro. J., ChemPhysChem, Angew. Chem. Int. Ed.); American Institute of Physics (Phys. Rev.); Institute of Physics Publishing (J. Phys. Condens. Matter); Taylor and Francis (Mol. Phys.).

\begin{abstract}
ADVANCES IN CHEMISTRY
A Selection of C.N.R. Rao's Publications (1994-2003)

Copyright @ 2003 by World Scientific Publishing Co. Pte. Ltd.

All rights reserved. This book, or parts thereof, may not be reproduced in any form or by any means, electronic or mechanical, including photocopying, recording or any information storage and retrieval system now known or to be invented, without written permission from the Publisher.
\end{abstract}

For photocopying of material in this volume, please pay a copying fee through the Copyright Clearance Center, Inc., 222 Rosewood Drive, Danvers, MA 01923, USA. In this case permission to photocopy is not required from the publisher.

ISBN 981-238-599-1 


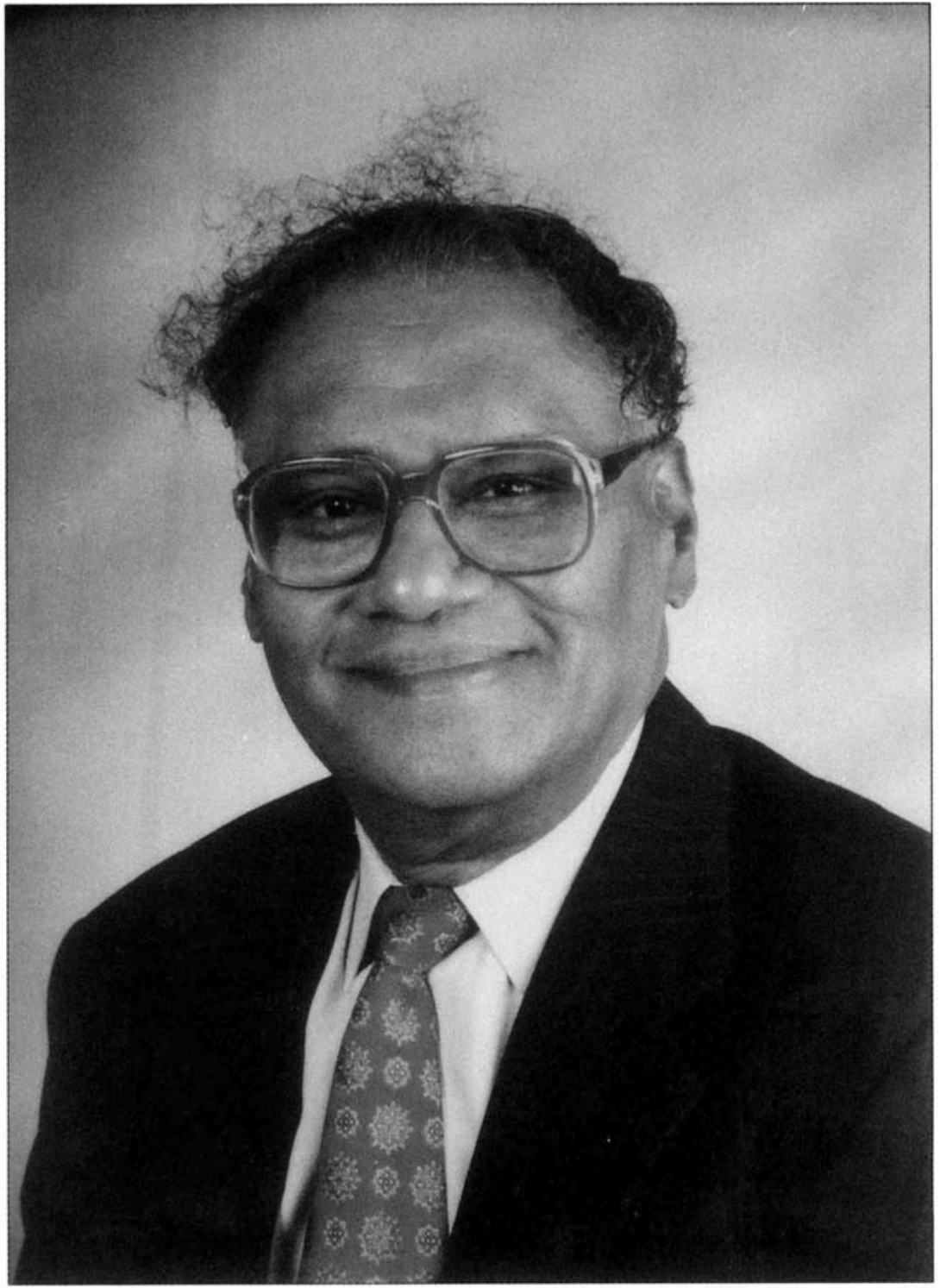

Professor C.N.R. Rao 
This page is intentionally left blank 


\section{FOREWORD}

Professor Chintamani Nagesa Ramachandra Rao (C.N.R. Rao) is a towering personality in Indian science in the post-Independence era, whose immense contributions span over five decades covering several facets of Chemical Sciences. Professor Rao's prolific research work delineated in more than 1200 publications and 36 books, has made an impact on a wide range of topics that include chemical spectroscopy, molecular structure, various aspects of the solid state - synthesis, structure and properties. To him, it concerns very little whether the system under investigation is organic, inorganic or a composite material, but it is the property or the phenomenon that interests him always. For example, he has worked with equal felicity on rutile-anatase, metalinsulator, plastic-crystalline, para-ferri-ferro magnetic transitions as well as on charge-ordering, phase separation, donor-acceptor complexes, superconductors, and last but not least, the fascinating field of fullerenes and nanomaterials.

Solid State and Materials Chemistry has been very close to his heart during the last two decades, where he has made significant contributions to the synthesis of novel materials, developing new routes to synthesis, copper oxide based superconductors, manganese oxide based magnetoresistive materials, among others. Particularly noteworthy is his unique work on porous and open-framework solids, where he has not only assembled a variety of crystalline architectures but also unravelled the fundamental principles governing the formation of structures of different dimensionalities. A natural extension has been into the fascinating world of the supramolecular chemistry, where for example, he has synthesized a novel organic zeolite and a hybrid solid containing layers of silver sheets separated by an organic spacer. He has established a world class research laboratory for the synthesis and investigation of nanomaterials in various forms of aggregation including clusters, tubes and wires; a special Y-junction nanotube showing rectification, doped gallium nitride nanowires and several nanoobjects based on transition metal chalcogenides are some of the important materials created in his laboratory.

It is with a profound sense of respect and gratitude to Professor C.N.R. Rao that we present to the scientific community, this monograph containing a selected collection of seventy of his research publications spanning the last one decade (1994-2003). It has not been an easy task to make this selection, especially because another set of equally important papers could have been easily collected from his 350 publications during 
this period. In making this selection, an effort has been made to bring out the flavour of Professor Rao's contribution to the entire gamut of Chemistry and Physics of Materials, in general. The collection of papers under different sections is preceded by Professor Rao's comments which embellish the contents with a personal touch. It must be added that such an elegant publication would not have been possible without the support from the Third World Academy of Sciences, Trieste, and the cooperation of the Publisher, World Scientific Publishing Co., Singapore especially, Dr. K.K. Phua, and Ms. Lakshmi Narayanan.

We do believe that the present volume will not only be treasured by his friends, close associates and admirers but also be cherished by young practitioners. For the two of us, it has indeed been a great privilege and honour to serve as Editors of this special monograph felicitating Professor C.N.R. Rao on his $7^{\text {th }}$ birthday.

May God Almighty bless him with many more years of research activity and highest scientific laurels!

G.U. Kulkarni

J. Gopalakrishnan 


\section{Contents}

I. Highlights of Materials Chemistry 1 C.N.R. Rao

1. Novel Materials, Materials Design and Synthetic 5 Strategies: Recent Advances and New Directions, J. Mater. Chem. 9, 1 (1999).

2. The Metal-Nonmetal Transition: A Global Perspective, (with P.P. Edwards and T.V. Ramakrishnan), J. Phys. Chem. 99, 5228 (1995).

3. Virtues of Marginally Metallic Oxides, Chem. Commun., 2217 (1996).

4. Phase Separation in Metal Oxides, (with P.V. Vanitha and A.K. Cheetham), Chem. Eur. J. 9, 829 (2003).

5. Science and Technology of Nanomaterials: Current Status and Future Prospects, (with A.K. Cheetham), J. Mater. Chem. 11, 2887 (2001).

II. Transition Metal Oxides (including Cuprate Superconductors) 53 C.N.R. Rao

6. Chemical Strategies for the Synthesis of Metal Oxides, 55 in Reactivity of Solids: Past, Present and Future, $A$ 'Chemistry for the $21^{\text {st }}$ Century' monograph, IUPAC, Ed. V.V. Boldyrev, Blackwell Science Publishers, Oxford, p. 237, 1996.

7. Solid-Solid Interfaces in the Epitaxial Films of Complex Oxides Deposited by Chemical Methods, (with A.R. Raju and H.N. Aiyer), in Interfacial Science, $A$ 'Chemistry for the 21 ${ }^{\text {st }}$ Century' monograph, IUPAC, Ed. M.W. Roberts, Blackwell Science Publishers, p. 1, 1997.

8. Sub-micrometre Spherical Particles of $\mathrm{TiO}_{2}, \mathrm{ZrO}_{2}$ and PZT by Nebulized Spray Pyrolysis of Metal-Organic precursors, (with P. Murugavel, M. Kalaiselvam and A.R. Raju), J. Mater. Chem. 7, 1433 (1997). 
9. A Study of Cubic Bismuth Oxides of the Type $\mathrm{Bi}_{26-\mathrm{x}} \mathrm{M}_{\mathrm{x}} \mathrm{O}_{40-\delta}$ $\left(\mathrm{M}=\mathrm{Ti}, \mathrm{Mn}, \mathrm{Fe}, \mathrm{Co}, \mathrm{Ni}\right.$ or $\mathrm{Pb}$ ) Related to $\gamma-\mathrm{Bi}_{2} \mathrm{O}_{3}$, (with N. Rangavittal and T.N. Guru Row), Eur. J. Solid State Inorg. Chem. 31, 409 (1994).

10. Effect of Cation Size and Disorder on the Structure and 109 Properties of the Rare Earth Cobaltates, $\mathrm{Ln}_{0.5} \mathrm{~A}_{0.5} \mathrm{CoO}_{3}$, (with P.V. Vanitha, A. Arulraj and P.N. Santosh), Chem. Mater. 12, 1666 (2000).

11. Orbital Ordering as the Determinant for Ferromagnetism in Biferroic BiMnO , (with A.M. dos Santos, A.K. Cheetham, T. Atou, Y. Syona, Y. Yamaguchi, K. Ohoyama and H. Chiba), Phys. Rev. B66, 64425 (2002).

12. Structure-Property Relationships in Superconducting

Cuprates, (with A.K. Ganguli), Chem. Soc. Rev., 1 (1995).

13. Stripes and Superconductivity in Cuprates - Is there a Connection? (with N. Kumar), ChemPhysChem 4, 439 (2003).

III. Colossal Magnetoresistance, Charge Ordering and Related Aspects of Rare Earth Manganates C.N.R. Rao

14. Colossal Magnetoresistance, Charge Ordering and Other Novel Properties of Manganates and Related Materials, (with A.K. Raychaudhuri), in Colossal Magnetoresistance, Charge Ordering and Related Properties of Manganese Oxides, Eds. C.N.R. Rao and B. Raveau, World Scientific, Singapore, 1998, p. 1.

15. Charge, Spin and Orbital Ordering in the Perovskite Manganates, $\mathrm{Ln}_{1-x} \mathrm{~A}_{\mathrm{x}} \mathrm{MnO}_{3}$ ( $\mathrm{Ln}=$ Rare Earth, $\mathrm{A}=\mathrm{Ca}$ or $\mathrm{Sr}$ ), J. Phys. Chem. B104, 5877 (2000).

16. Electron-Hole Asymmetry in the Rare-Earth Manganates: A Comparative Study of the Hole- and Electron-Doped Materials, (with K. Vijaya Sarathy, P.V. Vanitha, R. Seshadri and A.K. Cheetham), Chem. Mater. 13, 787 (2001). 
17. Electric-Field-Induced Melting of the Randomly Pinned

Charged-Ordered States of Rare-Earth Manganates and

Associated Effects, (with A.R. Raju, V. Ponnambalam,

S. Parashar and N. Kumar),

Phys. Rev. B61, 594 (2000).

18. Occurrence of Re-entrant Ferromagnetic Transitions in

202

Rare-Earth Manganates on Cooling the Charge-Ordered States, (with A.K. Kundu and P.V. Vanitha),

Solid State Commun. 125, 41 (2003).

19. Electronic Phase Separation in the Rare-Earth Manganates

206

$\left(\mathrm{La}_{1-\mathrm{x}} \mathrm{Ln}_{\mathrm{x}}\right)_{0.7} \mathrm{Ca}_{0.3} \mathrm{MnO}_{3}(\mathrm{Ln}=\mathrm{Nd}, \mathrm{Gd}$ and $\mathrm{Y})$,

(with L. Sudheendra),

J. Phys. Condens. Matter 15, 3029 (2003).

IV. Nanoparticles

219

C.N.R. Rao

20. Growth of Nanometric Gold Particles in Solution Phase

221

(with R. Seshadri, G.N. Subbanna, V. Vijayakrishnan,

G.U. Kulkarni and G. Ananthakrishna),

J. Phys. Chem. 99, 5639 (1995).

21. Size-Dependent Chemistry: Properties of Nanocrystals,

(with G.U. Kulkarni, P.J. Thomas and P.P. Edwards),

Chem. Euro. J. 8, 29 (2002).

22. Superlattices of Metal and Metal-Semiconductor Quantum

Dots Obtained by Layer-by-Layer Deposition of Nanoparticle

Arrays, (with K. Vijaya Sarathy, P.J. Thomas and G.U. Kulkarni),

J. Phys. Chem. B103, 399 (1999).

23. X-ray Photoelectron Spectroscopic Investigations of $\mathrm{Cu}-\mathrm{Ni}$,

$\mathrm{Au}-\mathrm{Ag}, \mathrm{Ni}-\mathrm{Pd}$ and $\mathrm{Cu}-\mathrm{Pd}$ Bimetallic Clusters,

(with K.R. Harikumar and S. Ghosh),

J. Phys. Chem. A101, 536 (1997).

24. Magic Nuclearity Giant Clusters of Metal Nanocrystals

Formed by Mesoscale Self-Assembly,

(with P.J. Thomas and G.U. Kulkarni),

J. Phys. Chem. B105, 2515 (2001).

25. Novel Effects of Metal Ion Chelation on the Properties of

Lipoic Acid-Capped Ag and Au Nanoparticles,

(with S. Berchmans and P.J. Thomas),

J. Phys. Chem. B106, 4647 (2002). 
C.N.R. Rao

26. Carbon Nanotubes from Organometallic Precursors, (with A. Govindaraj),

Acc. Chem. Res. 35, 998 (2002).

27. Production of Bundles of Aligned Carbon and

Carbon-Nitrogen Nanotubes by the Pyrolysis of Precursors

on Silica-Supported Iron and Cobalt Catalysts, (with M. Nath, B.C. Satishkumar, A. Govindaraj and C.P. Vinod), Chem. Phys. Lett. 322, 333 (2000).

28. B-C-N, C-N and B-N Nanotubes Produced by the 271

Pyrolysis of Precursor Molecules over Co Catalysts, (with R. Sen, B.C. Satishkumar, A. Govindaraj, K.R. Harikumar, G. Raina, J.-P. Zhang and A.K. Cheetham), Chem. Phys. Lett. 287, 671 (1998).

29. Boron-Carbon Nanotubes from the Pyrolysis of $\mathrm{C}_{2} \mathrm{H}_{2}-\mathrm{B}_{2} \mathrm{H}_{6}$ 277 Mixtures, (with B.C. Satishkumar, A. Govindaraj, K.R. Harikumar, J.-P. Zhang and A. K. Cheetham), Chem. Phys. Lett. 300, 473 (1999).

30. Novel Experiments with Carbon Nanotubes: Opening, 282 Filling, Closing and Functionalizing Nanotubes, (with B.C. Satishkumar, A. Govindaraj, J. Mofokeng and G.N. Subbanna), J. Phys. B29, 4925 (1996).

31. The Decoration of Carbon Nanotubes by Metal Nanoparticles,

292 (with B.C. Satishkumar, E.M. Vogl and A. Govindaraj), J. Phys. D29, 3173 (1996).

32. A Study of Micropores in Single-Walled Carbon Nanotubes by the Adsorption of Gases and Vapors, (with M. Eswaramoorthy and R. Sen), Chem. Phys. Lett. 304, 207 (1999).

33. Pressure-Induced Phase Transformation and the Structural Resilience of Single-Walled Carbon Nanotube Bundles, (with S.M. Sharma, S. Karmakar, S.K. Sikka, P.V. Teredesai, A.K. Sood and A. Govindaraj), Phys. Rev. B63, 205417 (2001).

34. Hydrogen Storage in Carbon Nanotubes and Related Materials, (with G. Gundiah, A. Govindaraj, N. Rajalakshmi and K.S. Dhathathreyan), J. Mater. Chem. 13, 209 (2003). 
35. Inorganic Nanotubes, (with M. Nath), Dalton Trans., 1 (2003).

36. Metal Nanowires and Intercalated Metal Layers in 334 Single-Walled Carbon Nanotube Bundles, (with A. Govindaraj, B.C. Satishkumar and M. Nath), Chem. Mater. 12, 202 (2000).

37. Synthesis of Metal Oxide Nanorods Using Carbon Nanotubes as Templates, (with B.C. Satishkumar,

A. Govindaraj and M. Nath), J. Mater. Chem. 10, 2115 (2000).

38. Nanowires, Nanobelts and Related Structures of $\mathrm{Ga}_{2} \mathrm{O}_{3}$, (with G. Gundiah and A. Govindaraj), Chem. Phys. Lett. 351, 189 (2002).

39. Synthesis and Characterization of Silicon Carbide, Silicon Oxynitride and Silicon Nitride Nanowires, (with G. Gundiah, G.V. Madhav, A. Govindaraj and Md. M. Seikh), J. Mater. Chem. 12, 1606 (2002).

40. Photoluminescence Spectra and Ferromagnetic Properties of GaMnN Nanowires, (with F.L. Deepak, P.V. Vanitha and A. Govindaraj), Chem. Phys. Lett. 374, 314 (2003).

VI. Molecular Solids C.N.R. Rao

41. Investigations of Diamond-Graphite Hybrids and Fullerenes 363 with Seven-Membered Rings, (with R. Sen, R. Sumathy and B.C. Satishkumar), J. Mol. Struct. 436-437, 11 (1997).

42. Polymerization and Pressure-Induced Amorphization of $\mathrm{C}_{60}$ and $\mathrm{C}_{70}$, (with A. Govindaraj, H.N. Aiyer and R. Seshadri), J. Phys. Chem. 99, 16814 (1995).

43. A Combined Experimental and Theoretical Study of the Charge-Transfer Compound between $\mathrm{C}_{60} \mathrm{Br}_{8}$ and Tetrathiafulvalene, (with A. Govindaraj, R. Sumathy and A.K. Sood), Mol. Phys. 89, 267 (1996). 
44. Hydrothermal Synthesis of Organic Channel Structures:

1:1 Hydrogen-Bonded Adducts of Melamine with Cyanuric and Trithiocyanuric Acids, (with A. Ranganathan and V.R. Pedireddi),

J. Am. Chem. Soc. 121, 1752 (1999).

45. An Organic Channel Structure Formed by the Supramolecular Assembly of Trithiocyanuric Acid and 4,4'-bipyridyl, (with A. Ranganathan, V.R. Pedireddi and S. Chatterjee), J. Mater. Chem. 9, 2407 (1999).

46. Self-Assembled Four-Membered Networks of Trimesic Acid Forming Channel Structures, (with S. Chatterjee, V.R. Pedireddi and A. Ranganathan), J. Mol. Struct. 520, 107 (2000).

47. A Novel Hybrid Layer Compound Containing Silver 401 Sheets and An Organic Spacer, (with A. Ranganathan, V.R. Pedireddi and A.R. Raju), Chem. Commun., 39 (2000).

48. Experimental and Theoretical Electronic Charge Densities in 403 Molecular Crystals, (with G.U. Kulkarni and R.S. Gopalan), J. Mol. Struc. (Theochem) 500, 339 (2000).

49. An Experimental Charge Density Study of the Effect of the 427 Noncentric Crystal Field on the Molecular Properties of Organic NLO Materials, (with R.S. Gopalan and G.U. Kulkarni), ChemPhysChem 1, 127 (2000).

VII. Porous Solids C.N.R. Rao

50. Evidence for Supramolecular Organization of Alkane and Surfactant Molecules in the Process of Forming Mesoporous Silica, (with N. Ulagappan), Chem. Commun., 2759 (1996).

51. Phase Transformations in Mesoporous Zirconia, (with Neeraj), J. Mater. Chem. 8, 1631 (1998).

52. Mesoporous Phases Based on $\mathrm{SnO}_{2}$ and $\mathrm{TiO}_{2}$ (with N. Ulagappan),

Chem. Commun., 1685 (1996). 
53. Mesoporous Aluminoborates, (with S. Ayyappan),

Chem. Commun., 575 (1997).

54. High Catalytic Efficiency of Transition Metal Complexes

449

Encapsulated in a Cubic Mesoporous Phase,

(with M. Eswaramoorthy and Neeraj),

Chem. Commun., 615 (1998).

55. Metal Chalcogenide-Organic Nanostructured Composites

from Self-Assembled Organic Amine Templates,

(with Neeraj),

J. Mater. Chem. 8, 279 (1998).

56. Synthesis of Hexagonal Microporous Silica and

Aluminophosphate by Suparmolecular Templating of a

Short-Chain Amine, (with M. Eswaramoorthy and S. Neeraj),

Micro. Meso. Mater. 28, 205 (1999).

57. Macroporous Oxide Materials with Three-Dimensionally Interconnected Pores, (with G. Gundiah),

Solid State Sci. 2, 877 (2000).

58. Macroporous Carbons Prepared by Templating Silica

Spheres, (with G. Gundiah and A. Govindaraj),

Mater. Res. Bull. 36, 1751 (2001).

VIII. Open Framework Materials

473

C.N.R. Rao

59. Aufbau Principle of Complex Open-Framework Structures of Metal Phosphates with Different Dimensionalities, (with S. Natarajan, A. Choudhury, S. Neeraj and A.A. Ayi), Acc. Chem. Res. 34, 80 (2001).

60. Understanding the Building-Up Process of Three

Dimensional Open-Framework Metal Phosphates:

Acid Degradation of the 3D Structures to Lower

Dimensional Structures, (with A. Choudhury),

Chem. Commun., 366 (2003).

61. A New Route for the Synthesis of Open-Framework

Metal Phosphates Using Organophosphates,

(with S. Neeraj, P.M. Forster and A.K. Cheetham),

Chem. Commun., 2716 (2001).

62. An Open-Framework Iron Phosphate with Large Voids

Exhibiting Spin-Crossover,

(with A. Choudhary and S. Natarajan),

Chem. Commun., 1305 (1999). 
63. An Unusual Open-Framework Cobalt(II) Phosphate with a Channel Structure that Exhibits Structural and Magnetic Transitions, (with A. Choudhury, S. Neeraj and S. Natarajan), Angew. Chem. Int. Ed. 39, 3091 (2000).

64. Organically Templated Mixed-Valent Iron Sulfates Possessing 492 Kagomé and Other Types of Layered Networks, (with G. Paul, A. Choudhury and E.V. Sampathkumaran), Angew. Chem. Int. Ed. 41, 4297 (2002).

65. Three-Dimensional Organically Templated Open-Framework Transition Metal Selenites, (with A. Choudhury and U. Kumar), Angew. Chem. Int. Ed. 41, 158 (2002).

66. Synthesis of a Hierarchy of Zinc Oxalate Structures from Amine Oxalates, (with R. Vaidhyanathan and S. Natarajan), J. Chem. Soc., Dalton Trans., 699 (2001).

67. Aliphatic Dicarboxylates with Three-Dimensional 508 Metal-Organic Frameworks Possessing Hydrophobic Channels, (with R. Vaidhyanathan and S. Natarajan), Dalton Trans., 1459 (2003).

68. Hybrid Open-Framework Iron Phosphate-Oxalates Demonstrating a Dual Role of the Oxalate Unit, (with A. Choudhury and S. Natarajan), Chem. Euro. J. 6, 1168 (2000).

69. Hybrid Inorganic-Organic Host-Guest Compounds: Open-Framework Cadmium Oxalates Incorporating Novel Extended Structures of Alkali Halides, (with R. Vaidhyanathan and S. Natarajan), Chem. Mater. 13, 3524 (2001).

70. Sodalite Networks Formed by Metal Squarates, (with S. Neeraj, M.L. Noy and A.K. Cheetham), Solid State Sci. 4, 1231 (2002).

Brief Biodata of Professor C.N.R. Rao 